\title{
Some thoughts and reflections on the use of illustration in Biodiversity Education Campaigns
}

\author{
Stephen D. Nash
}

Scientific Illustrator, Conservation International, Visiting Research Associate, Department of Anatomical Sciences, and Adjunct Associate Professor, Department of Art, S.U.N.Y. Stony Brook, New York, U.S.A.

Email: snash@ms.cc.sunysb.edu

\begin{abstract}
The need to appreciate the interconnectedness of all life on Earth has never been more important than it is today, as our own species, mostly through ignorance, threatens to unravel the rich biological tapestry of which we are a part, and upon which we ultimately depend. Art, and especially imagery, can play a crucial role in reestablishing the profound and vital link between ourselves as individuals and the natural world. Recognizing this, conservationists are making ever more use of illustration in education campaigns worldwide on behalf of endangered wildlife and ecosystems. In this article I have tried to articulate my own feelings about nature, to trace the path that led me to work in this specialized area of art, and to relate some of the lessons I have learned applying illustration to conservation.
\end{abstract}

Keyword: art and science; biological illustration; conservation education campaigns; flagship species; primates.

Date of online publication 26 February 2009 ISSN 0974-7907 (online) | 0974-7893 (print)

Editor: Sanjay Molur

\section{Manuscript details:}

Ms \# 01914

Received 29 December 2007

Final revised received 13 February 2008

Finally accepted 15 March 2008

Citation: Nash, S.D. (2008). Some thoughts and reflections on the use of illustration in Biodiversity Education Campaigns. Journal of Threatened Taxa 1(1): 119-125.

Copyright: @ S.D. Nash 2008. Creative Commons Attribution 3.0 Unported License. JoTT allows unrestricted use of this article in any medium for non-profit purposes, reproduction and distribution by providing adequate credit to the authors and the source of publication.

Author Details: Stephen D. NASH is a native of Great Britain, and has been Scientific Illustrator for Conservation International since 1989, producing images for conservation and biological publications. $\mathrm{He}$ is based at the State University of New York at Stony Brook, and is currently at work completing illustrations of every known primate taxon.

Acknowledgements: I am grateful to John Aguiar and Matthew Richardson, both much better wordsmiths than I, for their very helpful comments on the text of this article.

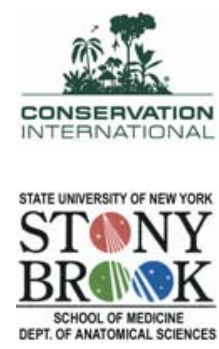

OPEN AGGESS I FREE DOWNLOAD
The origins of Art - whether in the form of pictures, film, theater, sculpture, or music - are still a matter of intense academic debate. What is without question, though, is that its appeal is widespread - and indeed perhaps almost universal, with vast potential for use in conservation education.

When working on a drawing for the purpose of conveying to the viewer the form and beauty of one of our fellow-primates perhaps, or a rhinoceros, or a toad, or a fish, I am acutely aware that what I am doing is part of a tradition that goes back in history certainly 33,000 years, and probably much, much further.

As John Berger (1980) points out in his essay 'Why Look At Animals?', the first symbols for humankind were animals, the first paint was probably animal blood, and for thousands of years the human experience of the world was charted using animal signs. The relationship between our species, Homo sapiens, and all of Earth's other inhabitants has undergone many changes over the millennia, but has always remained interconnected.

We are now, however, at a crucial point in both our own history, as well as that of our planet. Quite simply: the impact we are having upon the environment - and upon all of the other life forms among which we have developed - is now so devastating that we have the power to eradicate most of the species on the planet within a very short time.

If that should happen - if the predicted human-caused "extinction spasm" does occur - it will be mainly owing to our ignorance of the interdependence of life on earth. Moreover, such a catastrophe would I fear precipitate a decline in the quality of human life so profound that, although it might take generations to realize, would ultimately be inimical to our own continued survival.

The $19^{\text {th }}$ Century Native American Chief Seattle put it in this way: 'If all the beasts were gone, men would die of a great loneliness of spirit, for whatever happens to the beasts happens to the man. All things are connected...', more recently, the biologist E.O. Wilson (1984) has written of what he terms 'biophilia' - a need we feel for the presence of other creatures around us, essential for the continued health of our own species.

We express this biophilia clearly and strongly while young, when we are fascinated by stories and images of, and actual encounters with, animals. In my opinion, our own innocence at that stage of our lives finds obvious resonance in other beings who are similarly uncomplicated by the sophistications of adulthood.

It is also as children that our sense of wonder is at its strongest, as it was during the infancy of our species. The ancient images found on the rock walls of caves or canyons or on boulders in France, Tanzania, Australia, and elsewhere are among the most evocative renderings ever created. The ability to be amazed at the variety of life in all its manifestations can be dulled or even extinguished later in life, usually by the influence of other adults, but - in my view - it remains a key feature of what it is to be truly human.

These feelings are what lies behind the drawings that I produce for conservation education campaigns, blending what I hope is scientific accuracy with something less obvious, possibly irrational, and perhaps in some way childlike. Always at the back of my mind are thoughts of our own future, of our own long-term well being as a species.

Perhaps subconsciously, I see the possibility of people becoming re-acquainted with 

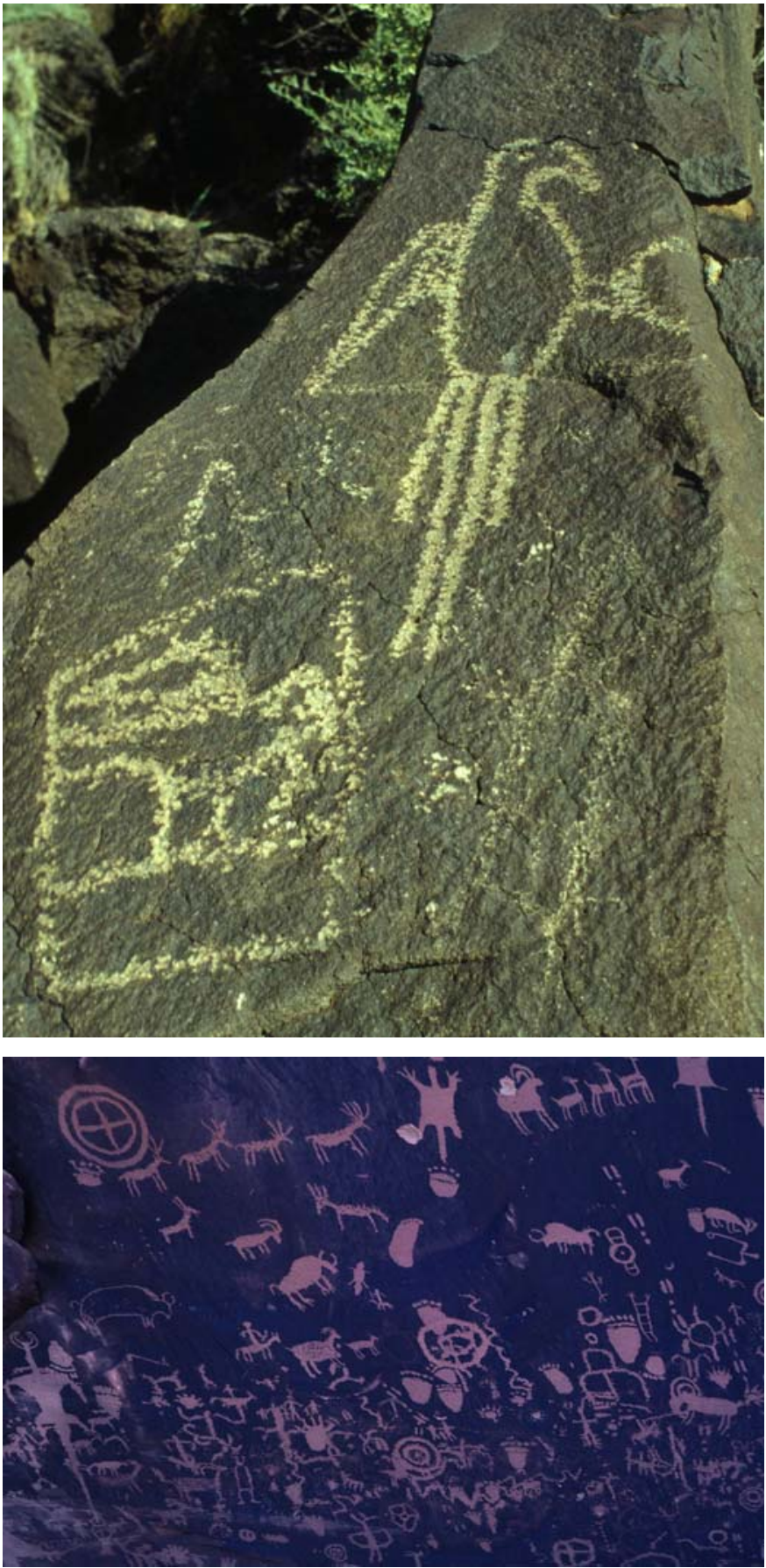

Image 1 (Above). An example of Native American rock art in Petroglyph National Monument in New Mexico, in the southwestern United States.

Image 2 (Below). Newspaper Rock, in Utah, in the

southwestern United States, is a wonderful example of Native American rock art or petroglyph.

Their meaning and function are still not clearly understood (Photos by Stephen D. Nash)

animals and plants through art, and thus reawakening their own sense of wonder. The most realistic and detailed rendering of a plant, for example, is an incomparably poor substitute for the living original, but it has its value as a product of observation, inspiration, and even veneration. It is an attempt at understanding, and an attempt at encouraging others to do the same.
During my years at art college in England, I would regularly visit the London Zoo, where we students were encouraged to draw whichever animals appealed to us. As I worked, I had the opportunity to listen to the conversations and comments of other visitors as they beheld the same creatures as me, and I noticed that two groups of animals in particular would elicit strong responses, both positive and negative, in the zoo-going public. I have since come to believe that this is a world-wide phenomenon, one that was examined in some detail in two books by Desmond Morris - 'Men and Apes' (1966) and 'Men and Snakes' (1965).

The two groups of animals that I speak of are, of course, the primates and the reptiles. Monkeys and apes can remind us, by their behaviors and appearance, that we share almost all of our genetic code with them, and are therefore linked with them to all other mammals. This can be comforting and enlightening to some people, and unsettling or even horrifyingly offensive and frightening to others.

In the same way, such creatures as snakes, lizards and turtles are either endlessly-fascinating "living jewels", or else disgusting, primitive and worthless vermin, depending upon the individual's point of view. The result of having observed these reactions among my fellow zoo-goers was to make me especially interested in, and sympathetic towards, the animals in question.

Just a few weeks ago I visited Disney's Animal Kingdom in Florida, where I was reminded of the huge influence that the films and images of Walt Disney and the organization he founded have had on what are now several generations of people around the world. It is an influence which some find controversial, but I personally see it as more and more reinforced and validated by current research, in that Disney encouraged us to see and treat animals as individuals, as living beings far more complex than the virtual automata of the old Cartesian philosophical system.

To me, the kinship between our own species and all others is obvious, but to openly acknowledge this can be disturbing to many people, because of the possible consequences to their established world-view and to the prevailing economic, cultural and even dietary norms. (Everyone 'draws the line' of compassion somewhere: I personally have been a vegetarian for all but the first six years of my life).

My own introduction to art came, at a very young age, through the medium of the comic book. The antiquity, subtlety and universality of the visual story-telling techniques to be found in these publications has been demonstrated with great eloquence and thoroughness by such authors as Scott McCloud (1993) and Will Eisner (1985). Moreover, the comic book format has been used very successfully even for conservation education

Comic book art is often highly economical in its detail, but in the best examples, what the artist leaves out is supplemented by the mind of the reader, with a potential for a powerful immersion in the story. All art is, to a greater or lesser degree, 'abstract', in that not every detail can (or indeed should) be included, and the influence of comic book art is evident in the pen and ink monochrome drawings I have included here as examples.

Comics have not been my only source of inspiration, however. Another important influence has been that of the Victorian Natural History illustrators, such as Joseph Wolf (see Schulze-Hagen \& Geus 2000), Frederick William Frohawk 


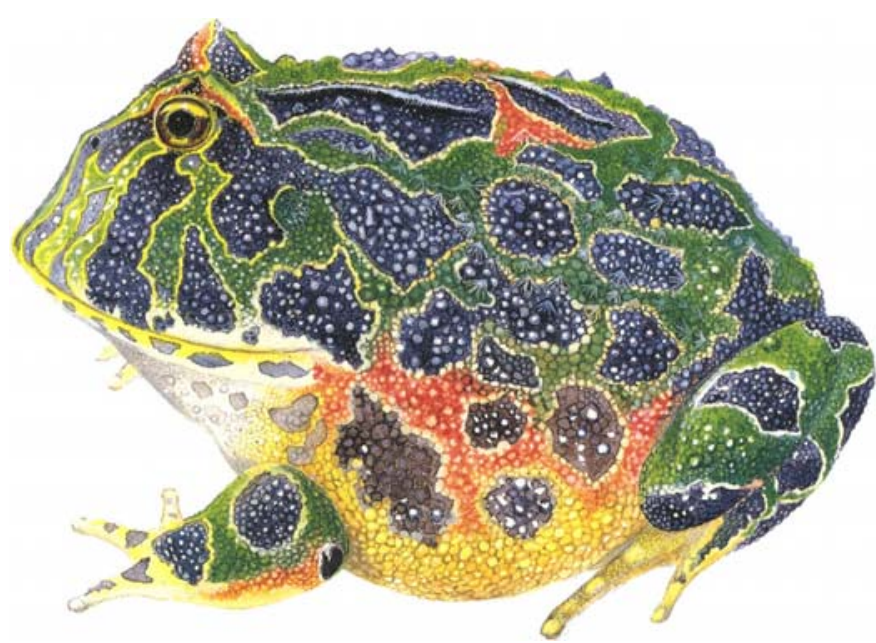

Image 3. A painting of an ornate horned frog by John Norris Wood, whose commitment to conservation was, he says, engendered during his childhood by encounters with Black Elk, the Oglala Lakota Sioux author and spiritual leader, and the illustrations of Edward Lear, among others. At the Royal College of Art, John organized a very active ecology study group in collaboration with Christopher Cornford, the late art historian and great-grandson of Charles Darwin. I can still vividly remember the group discussions, trips and wonderful talks by invited speakers.

(see Chatfield 1987), and especially Edward Lear (see Davidson 1933; Lehmann 1977; Chitty 1989), whose compassion for his animal subjects was as great as his artistic talent. His drawings of parrots and tortoises in particular are considered among the finest ever created, but he was also able to communicate his wonder equally well through his poetry.

Lear disliked having to work from anything other than living subjects, but that was by no means always possible, and even those artists who accompanied scientific expeditions often had to draw dead specimens. This presented many difficulties and often resulted in distorted, unnatural postures and features.

Leonardo da Vinci's own acute sensitivity and empathy is shown in his frequent purchase, and subsequent release, of caged birds from markets in the towns where he lived. He wrote: "I have from an early age abjured the use of meat, and the time will come when men such as I will come to look upon the murder of animals as they now look upon the murder of men”. This did not, however, prevent him from conducting anatomical investigation, in the form of dissections, of both animal and human subjects

Da Vinci's desire to know his subjects 'from the inside out' by trying to understand their anatomy is one that I too understand, and for a few years I was intent upon pursuing a career in medical illustration. Even today, I often consult old comparative anatomical illustrations of an animal before embarking on a drawing, especially if the species has been rarely photographed.

While at college I was fortunate to be taught by a number of gifted illustrators, and two in particular - despite fundamental differences in their methods and approaches - have had a profound influence upon me and my work, and deserve mention here. Both have recently retired from teaching.

One is Edward O.Z. Wade, whose exquisite and meticulous drawings and paintings, especially of reptiles and amphibians, are done almost exclusively from prepared dead specimens. His enthusiastic and generous sharing of his encyclopaedic knowledge of taxonomy and its history and development was a wonderfully illuminating experience.

The other major influence on my work, John Norris Wood, only very reluctantly works from anything other than a living creature, and strives to capture in his illustration the character of his subject rather than a scale-by-scale likeness. John's most passionate interest is also in the reptiles and amphibians.

Both of these illustrators dearly love the animals they portray, and to me it is powerfully evident in their work. A drawn, painted, or sculpted image is as open to analysis, as revealing, and ultimately as personal, as any piece of handwriting. I think it is inevitable that a part of the artist is left in the artwork once it is completed, and such subtle residues can certainly augment a verbal message, whether intentionally or not, communicated at a very deep level. The genuine power of the artist's concern for his subject will always come through.

Yet it was to take the foresight, imagination, and courage of another individual, not an artist himself, to see the potential contribution of imagery to modern biodiversity conservation efforts, and to take that vision further than anyone else to date. That person is Russell Mittermeier, President of the Arlington, Virginia-based organization Conservation International. In the quarter-century that I have worked for him I have taken on what to me have been the most daunting artistic challenges I have ever faced, not the least being a project to illustrate every taxon of the primate order.

This ambitious (some would say foolhardy) undertaking, which I established as a personal goal while a student, has been lately informed with more significance, urgency and energy by my own research into my ancestry. As I have delved deeper and deeper in time, moving away from the recent, outermost leaf tips of my family tree towards the comparatively ancient trunk, it has become ever more obvious how closely related all of humanity really is. So it is that it has been really quite easy to take the next step and acknowledge, not just intellectually but viscerally, our close relationship with our zoological 'cousins', the primates.

Beyond even this realization comes the acceptance of our membership of a global family that includes all life on the planet. This is not a new concept, of course, and it has been part of many philosophies and religions for centuries before recent scientific breakthroughs, especially in the field of genetics, have given it scientific weight. My work has become for me a celebration of this personal acknowledgment of these wider connections.

The Muriqui (Brachyteles arachnoides) of the Atlantic Forest of eastern Brazil was the subject of the first 'image experiment' in primate-focused conservation education with which I was involved. The largest and most ape-like of the New World monkeys, its original distribution lay in the region first colonized by the Portuguese in the early 1500s; today, five centuries later, the handful of remnant muriqui - now split into distinct northern and southern species - are surviving not so far from some of the largest cities in the world, including São Paulo and Rio de Janeiro.

In 1982, Muriquis were little known outside of eastern Brazil, and public awareness was confined to the available primatological literature. At the time we began our campaign, the animal did not even have a clearly-defined identity; within Brazil it was called either 'o mono', which means only 'the monkey', 


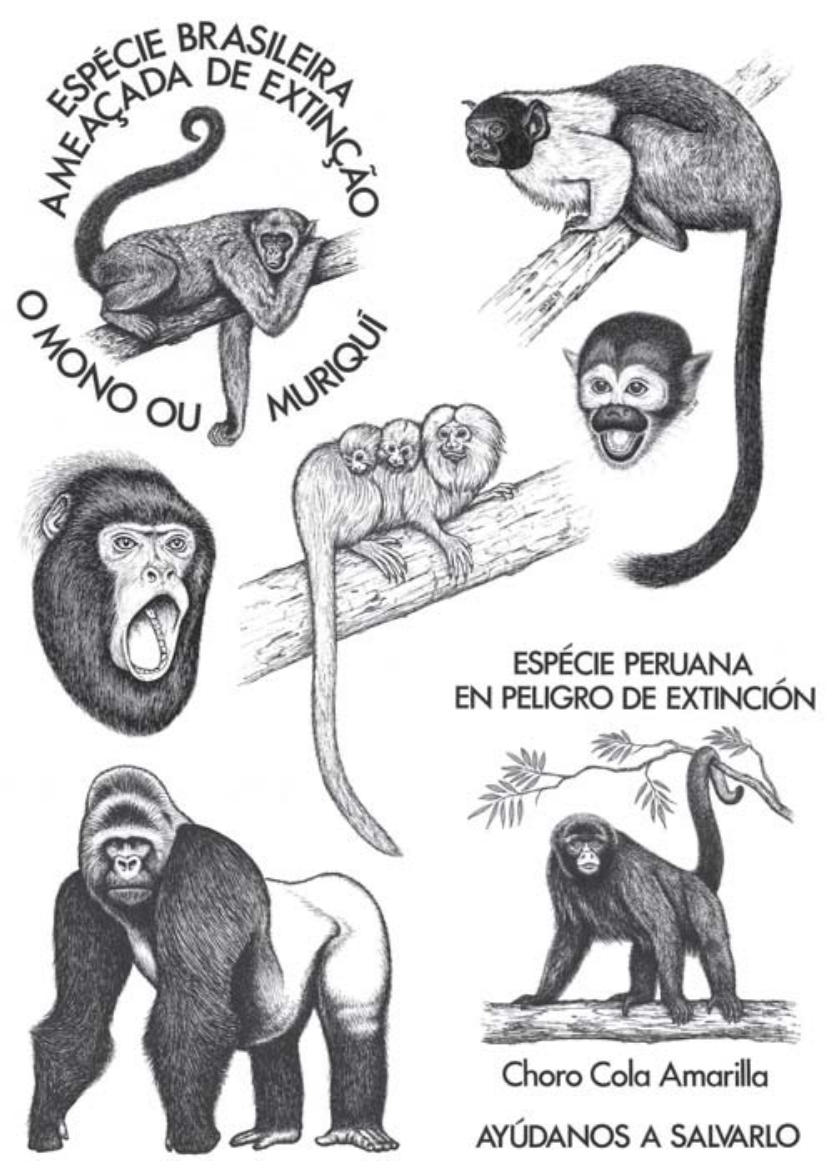

Image 4. Examples of drawings done during the 1980s for education purposes. With added messages, the images were printed on t-shirts, stickers and other materials. In later years, full-color printing became more economical. (Illustrations by $\mathrm{Cl} /$ Stephen D. Nash)

or 'mono carvoeiro' ('charcoal-burner monkey'), while in English it was given the misleading appellation of 'woolly spider monkey'.

The local Brazilian Indian name 'muriqui' seemed to be the most appropriate, and so, Dr. Mittermeier and his Brazilian colleagues orchestrated an education campaign. I produced a number of designs for posters, stickers, and t-shirts - including designs showing the other local primate fauna, and teams distributed these materials throughout the Atlantic Forest region.

The impact of the muriqui campaign was astonishing, and it catalyzed an entire homegrown response, the animals appearing on everything from local phone book covers and postage stamps to newspaper cartoons, and even snack food packaging - a phenomenon that continues to this very day.

Since then I have contributed to campaigns that have used animals, and even plants, of many sizes, shapes and taxonomic orders as 'focal' or 'flagship' species. And why not? Each has a unique characteristic - be it taxonomic, biogeographic or otherwise - which can help it represent entire endangered ecosystems.

The Indri (Indri indri), like the Muriqui, has the distinction of being the largest nonhuman primate in the country in which it lives. This lemur comes from the island nation of Madagascar, where these prosimian primates historically flourished in isolation from competition from monkeys and apes until the arrival of humans a few thousand years ago. With a very

\section{Reserva Particular Patrimonio Natural Feliciano Miguel Abdalla Private Nature Reserve}

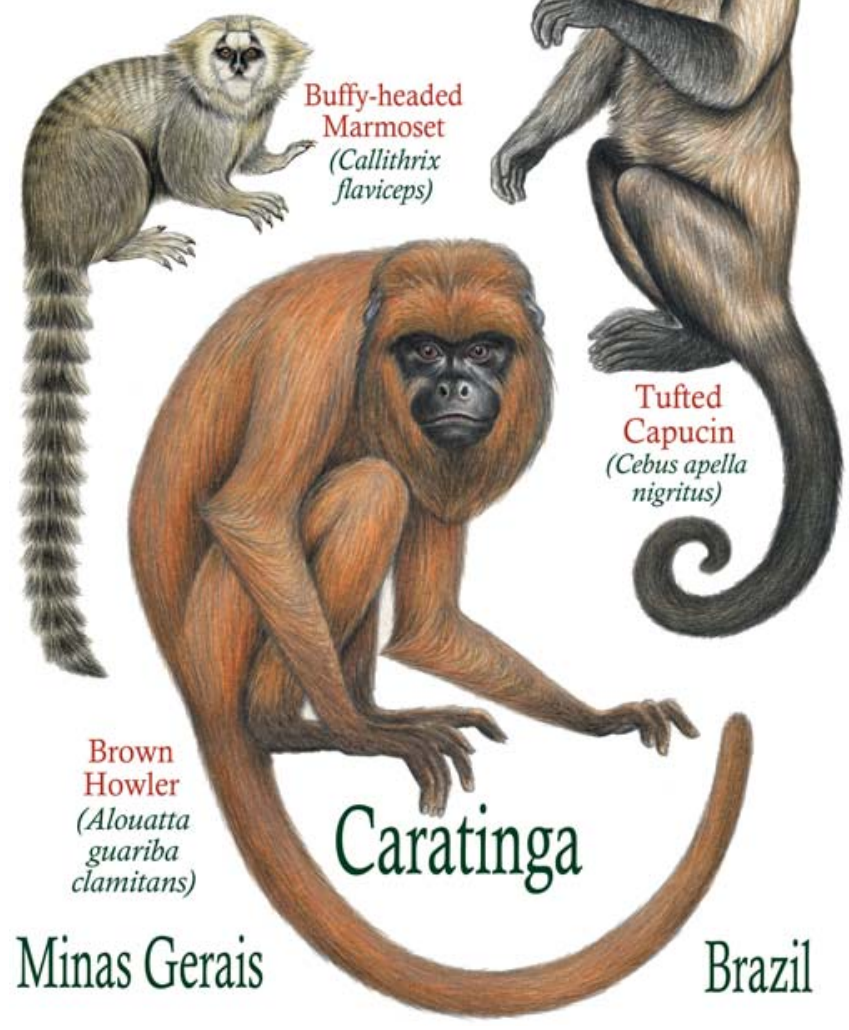

Image 5. The back of a shirt design produced to celebrate the official protection of a particular patch of forest in the north of the Muriqui's range, showing the other monkeys which also occur there. (IIlustration by Cl/Stephen D. Nash)

distinctive black and white coloration and haunting, powerful vocalizations, the Indri makes a very appealing flagship species for the rapidly vanishing rainforest biome in Madagascar.

The Indri's striking beauty and endemism should qualify it for national animal status, and one of its local names, 'babakoto', or 'ancestor of man', is indicative of the high esteem in which it is held by most Malagasy. The t-shirts worn by members of the Association of Guides of Andasibe prominently feature the Indri, but also depict the area's other lemurs, and constitute a sort of 'wearable field guide', an educational aid which we have experimented with elsewhere in Madagascar as well as in Ivory Coast and Indonesia.

There is no doubt that in the past quarter century we have learned many important lessons. One 


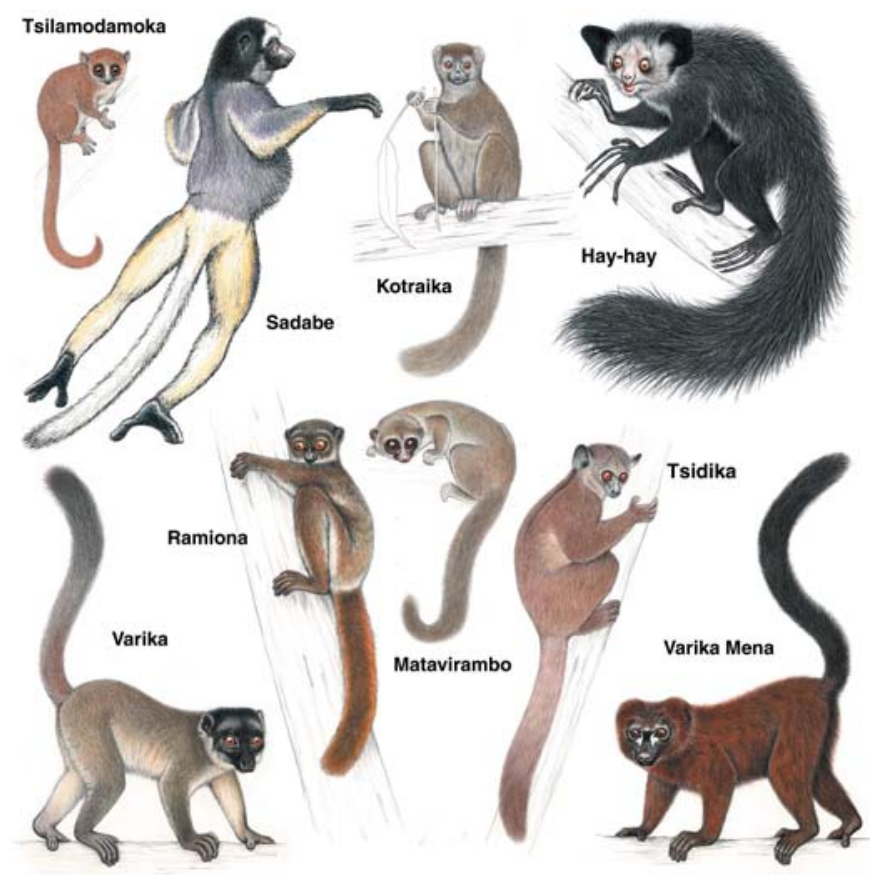

Image 7. In Madagascar, several experimental "wearable primate field guides" have been distributed. This is the back of one, with all of the animals' local names indicated, worn as a sort of uniform by all the guides at the local protected areas. (Illustration by Cl/Stephen D. Nash)

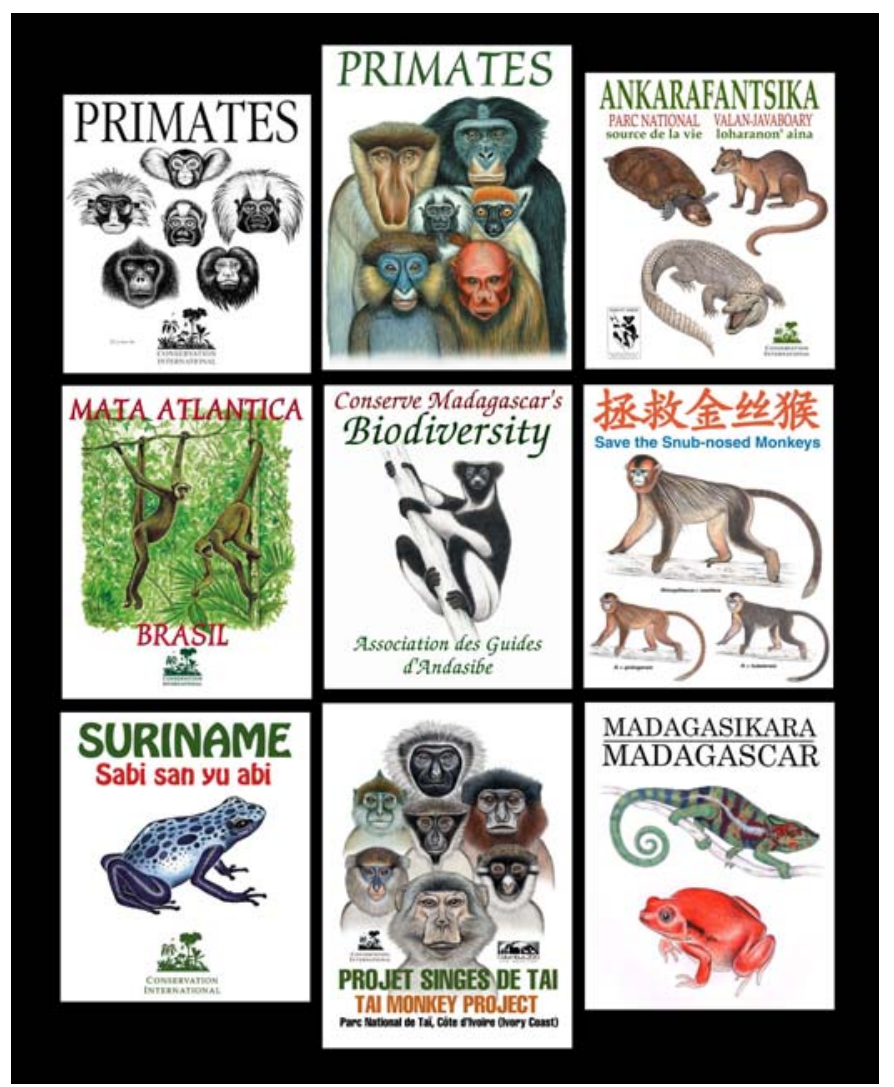

Image 8. Some examples of t-shirt designs created for various projects. The colors of the Malagasy flag are red, white and green, like the animals in the illustration at bottom left. (IIlustrations by $\mathrm{Cl} /$ Stephen $\mathrm{D}$. Nash)

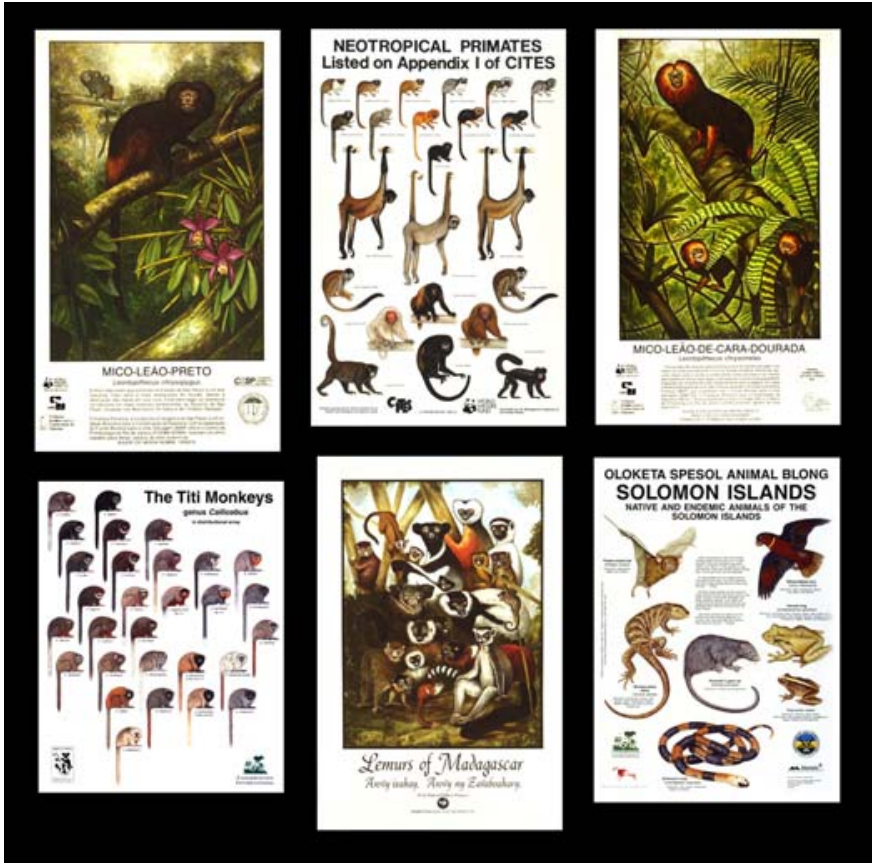

Image 9. These posters are some of the many produced as part of educational campaigns over the years. The one in the center at the top has been used by customs officials to identify endangered primates being trafficked under false names. (IIlustrations by Cl/Stephen D. Nash)

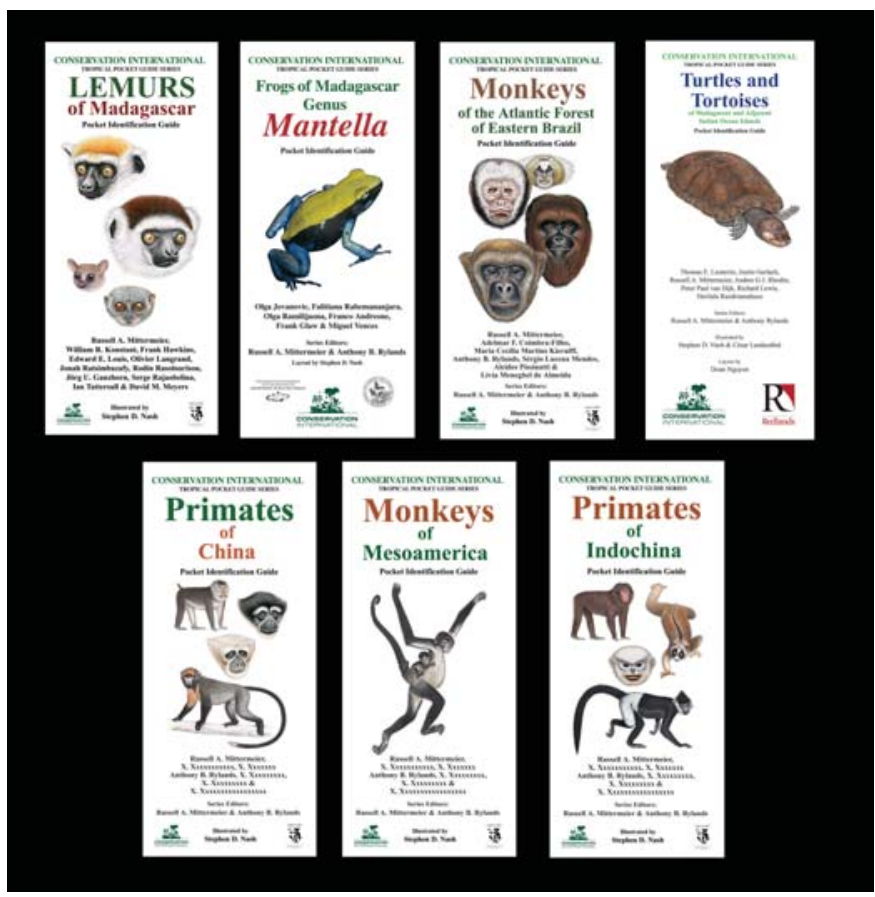

Image 10. Laminated pocket guides. These compact publications are much less vulnerable to the rigors of the tropical climate, and include checklists so that users can document their sightings, and thereby contribute to the pool of scientific data. (Illustrations by $\mathrm{Cl} / \mathrm{Stephen} \mathrm{D}$. Nash) 
concerns the importance of customizing education materials to the culture and even the climate of the place in which the campaign is to be conducted. This may seem obvious, but, for example, full-size posters quickly disintegrate in a humid tropical environment, whereas shirts and laminated miniposters do not. Stickers are not appropriate for communities where walls do not exist.

Another lesson learned is the importance of the supporting role that can be played by organizations such as the Guild of Natural Science Illustrators, or G.N.S.I. This very active and wonderfully friendly group of people, founded by staff illustrators in the Smithsonian Institution in 1968, now has almost a thousand members worldwide who share insights, techniques and experiences through G.N.S.I.-sponsored conferences and publications. The organization has always encouraged scientific illustrators from developing countries to join, and I have seen first hand how this sort of help can result in excellent materials being designed and produced in the places where endangered animals and plants actually survive.

At a recent meeting of scientists involved in conservation education, I met a young Peruvian scientist studying the seriously endangered Yellow-tailed Woolly Monkey (Oreonax flavicauda). She spoke of having discovered some of our education materials from the 1980 s in a museum storeroom, and of the need to resurrect the campaign on the animal's behalf today. It was a reminder that conservation education campaigns

\section{ESPÉCIE PERUANA EN PELIGRO DE EXTINCIÓN}

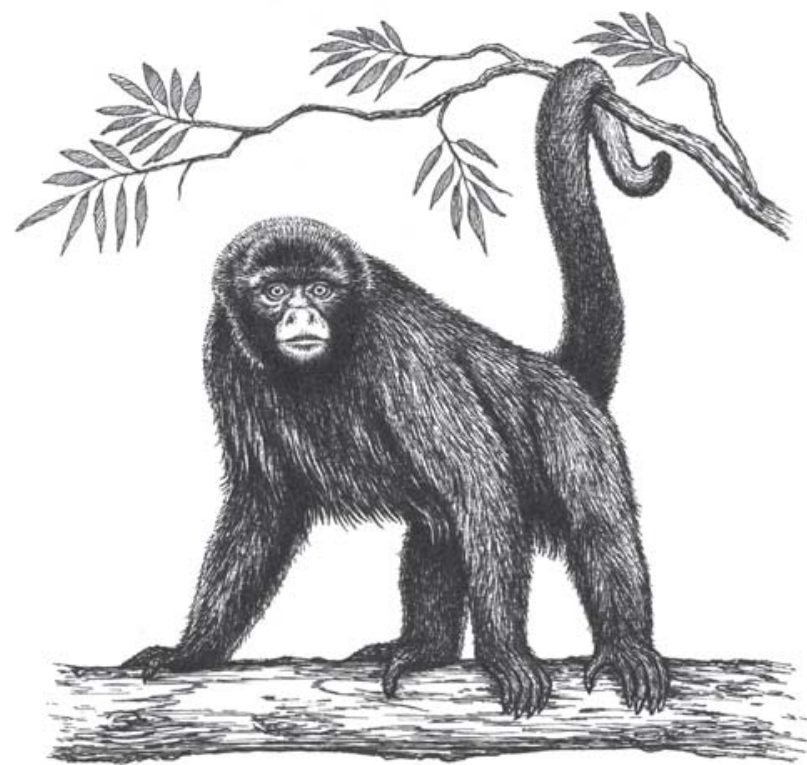

\section{Choro Cola Amarilla}

\section{AYÚDANOS A SALVARLO}

Image 11. The Yellow-tailed Woolly Monkey design used for stickers and t-shirts in the campaign. (IIlustration by $\mathrm{Cl} / \mathrm{Stephen}$ D. Nash)

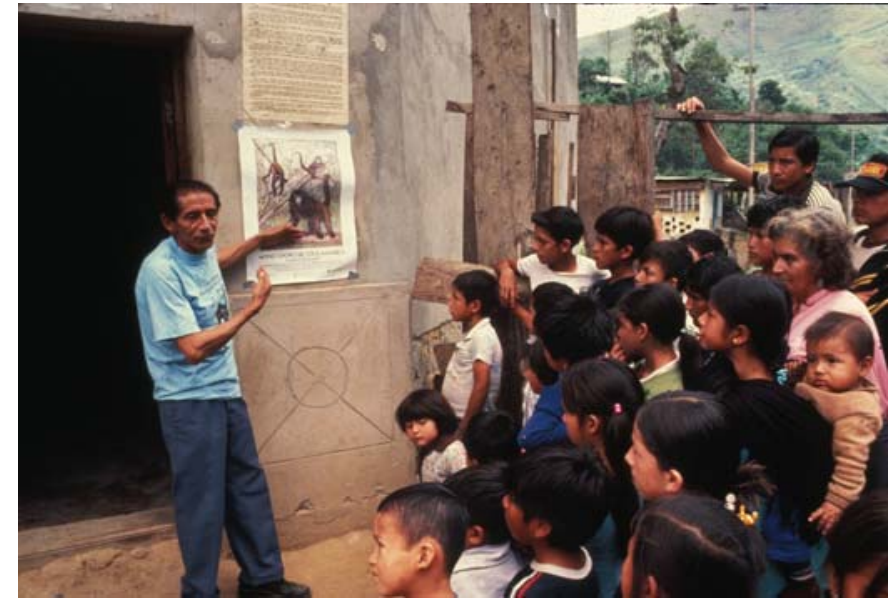

Image 12. The rediscovery, in 1983, of the Peruvian Yellowtailed Woolly Monkey, which had been considered extinct for decades, prompted the launch of another campaign, using the one on behalf of the Muriqui as a model. On the left is a former hunter speaking to local children of the importance of the monkey and its equally endangered cloud forest habitat. Behind him is a poster showing the animal. (Photo by Russell A. Mittermeier)

must be continuous, and that the focal species must become a permanent part of the local culture, and a source of pride from generation to generation.

The Yellow-tailed Woolly Monkey is in fact a perfect example of the interdependence within an ecosystem: The monkey's Andean cloud forest habitat absorbs, and slowly but continuously releases, rainwater which is vital for the rice fields on the mountains' lower slopes. If the forests are destroyed, the monkey and the other local wildlife will become extinct and rice cultivation will no longer be possible as the fields are destroyed by floods and drought.

Just as the health of human societies and that of the environment are mutually dependent, any separation of the Arts and the Sciences is artificial and undesirable, especially in the face of the many serious ecological challenges facing us today. People of all backgrounds can, and must, play a role in the maintenance of the earth's biodiversity, which is, I believe, our biological extended family as well as our long-term support system.

\section{REFERENCES}

Berger, J. (1980). "Why Look At Animals?", in "About Looking”. Readers and Writers Publishing Cooperative, London.

Chatfield, J. (1987). "F. W. Frohawk: His Life and Work". Crowood Press, Ramsbury, Wiltshire.

Chitty, S. (1989). "That Singular Person Called Lear". Atheneum New York. Davidson, A. (1933). "Edward Lear". John Murray. London.

Eisner, W. (1985). "Comics and Sequential Art”. Poorhouse Press. Tamarac, Florida.

Hodges, E. (1989) (Ed.). "The Guild Handbook of Scientific Illustration". Van Nostrand Reinhold, New York.

Lehmann, J. (1977). "Edward Lear and His World". Thames and Hudson, London.

McCloud, S. (1993). “Understanding Comics”. Harper, New York

Morris, R.D. (1966). "Men and Apes". Hutchinson, London.

Morris, R.D. (1965). "Men and Snakes". Hutchinson, London.

Schulze-Hagen, K. \& A. Geus (2000) (Eds.). "Joseph Wolf (1820-1899) Animal Painter". Basilisken-Presse, Marburg an der Lahn, Germany.

Wilson, E.O. (1984). "Biophilia". Harvard University Press, Cambridge, Massachusetts. 


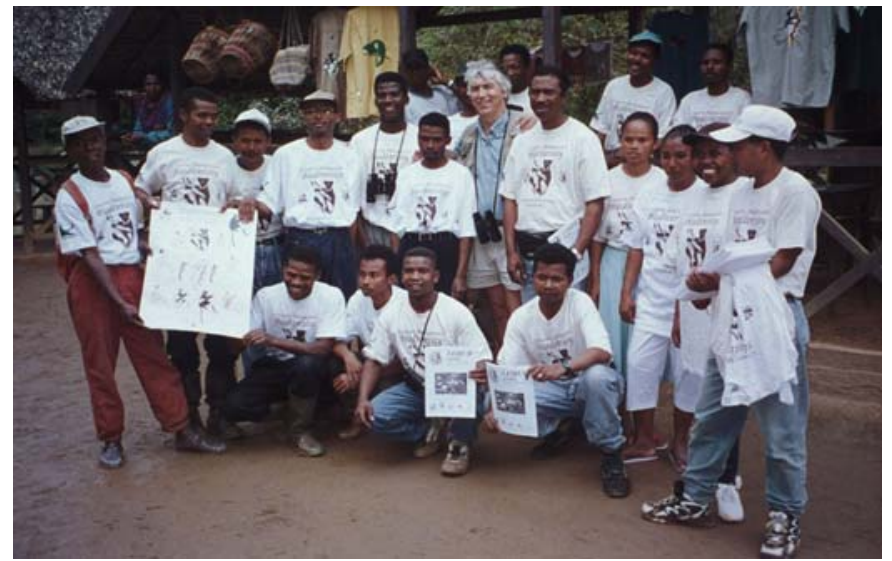

Image 13. In this photo, members of the Association of Guides at Andasibe in Madagascar are assembled in front of their Gift Shop, with President of Conservation International, Dr. Russell Mittermeier, in their midst. They are intensely and justifiably proud of their skills in tracking and locating the animals in their protected area, which is one of the most visited in the country. As well as t-shirts and publications, locally made handicrafts are sold at the shop. (Photo by William R. Konstant)

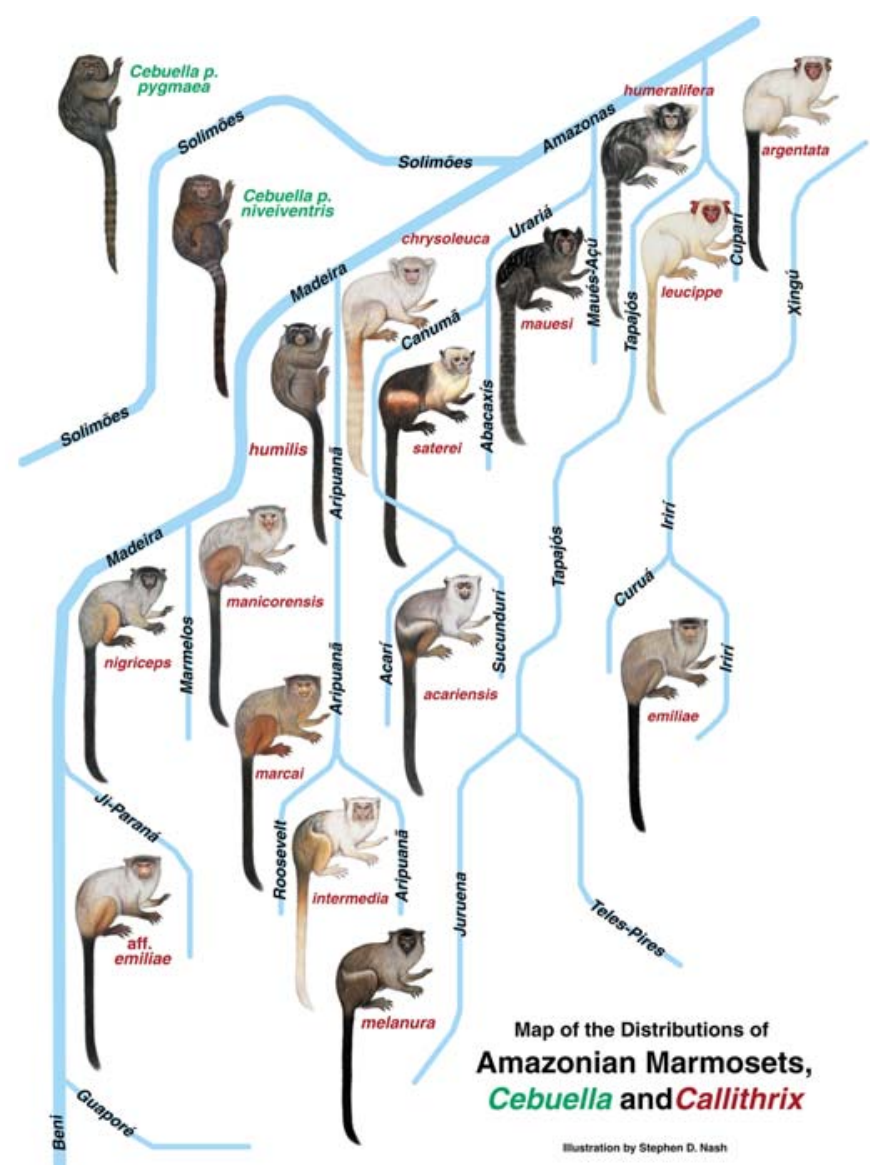

Image 14. Inspired by the map of the London Underground (subway) system, I produced this diagram of the distributions of the Amazonian species of marmosets to include some of the newly discovered creatures, but this shows only the major river systems. Interestingly, when more detailed maps are plotted with the known distributions, many question marks remain. Such semi-abstract visual solutions can sometimes be useful in conveying complex graphic information. (IIlustration by Cl/Stephen D. Nash)
Ny ala voho ñy biby ro harea, ñy fiarova azy ro mampandroso

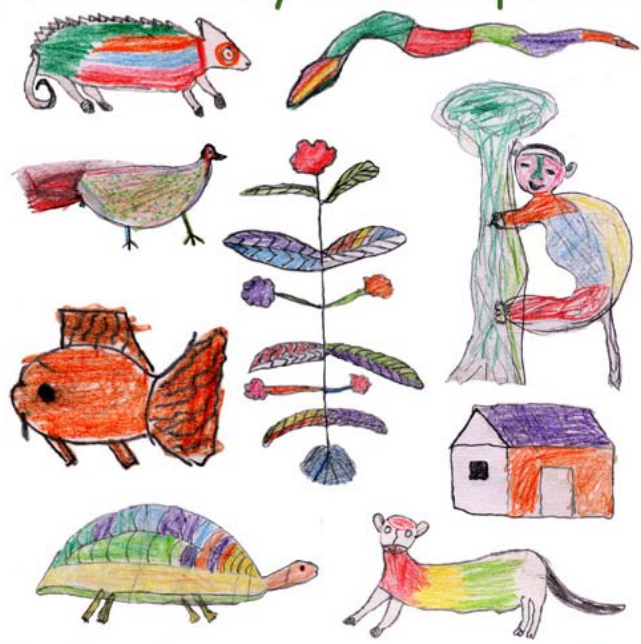

La forêt et les animaux sont nos richesses; leur conservation mène au développement

Image 15. This design is made up of drawings of wildlife produced by Malagasy children. Ultimately, the fate of Earth's wild creatures is in the hands of local people, who must be part of every campaign.

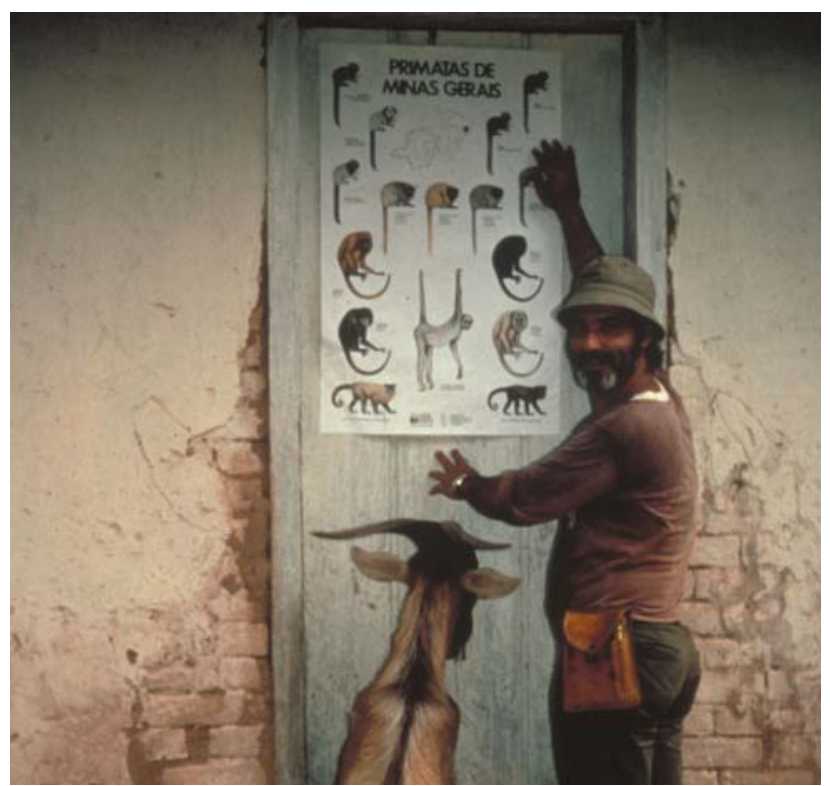

Image 16. Research and education team member Carlos Alberto Machado Pinto distributing posters showing the primates of the southeastern Brazilian state of Minas Gerais. (Photo by Russell A. Mittermeier) 